\title{
Translation: An Inter-Cultural Textual Transference
}

\section{Shamala Ratnakar}

\begin{abstract}
Translation is widely understood as the rendering of a text from one language to another that is from the Source Text (ST) and Source Language (SL) to the Target Text (TT) and Target Language (TL). Translation is not just a transfer of meanings contained in one set of language signs into another set of language signs through competent use of the dictionary. The process of translation involves along with linguistic ones the extra-linguistic preoccupations. These extralinguistic requirements include the transference of culture of the source text to the target text without primary distortions in the source text. Because translation is the representation of the culture of the source text into the target text which the translator does by replacing the source culture shown in the foreign language text by representing the equivalent meanings which are acceptable for the target language culture. In the process, the responsibility falls on the translator who has to preserve the culture of the source text and has to be faithful to the intentions of the source text. A study of the history of Translation Studies reveals the ways in which the source texts are rewritten, re-cast, adapted, transliterated, transformed, transcreated, and it also exposes the routes through which innovations are introduced in the translation field. Discussions on the theory of translation generally give short shift to the transference of culture as an important aspect of translation activity. The present paper proposes to reflect the differences among the cultures, the cultural transference and the extra-linguistic difficulties involved in the process of literary translation. It also illustrates how the translators overcome some of the problems of cultural issues how the process of transferring cultures through literary translations becomes a complicated and a vital task.
\end{abstract}

The culture that is "the customs, ideas and social behaviour of a particular people or group" (Soanes \& Stevenson 
2008:349) shape the text of any writer. Culture is that complex collection of experiences which condition the daily life of people belonging to particular language group and region. Culture includes the traditional customs and usages of everyday life of people, the history, the social structures, and the religion of a given society. It also relates to the inter-relationship among the people belonging to various social classes and religious groups which exist in close relationship with one another in any given society. This kind of culture is bound to influence the formation of literature. "Literary systems do not occur in a void, but in the ideological milieu of an era" (Gentzler 2004:136). The society is the constellations of these systems which vary from one region to another, from one country to another.

This social system invariably controls the literary system. And this literary system when crosses the boundaries of its origin travels along with its social and cultural system. Translation is to "secure the relations between literature and its environment" (Hermans 2004:126). The translation aims at conveying the cultural environment of the source text to the target text. In the process, the linguistic knowledge of the source as well as target text on the part of the translator is not just enough. The translator's knowledge of the cultural aspects of the source text is of utmost importance. The translator should be able to transfer the cultural connotations of the sign systems of the source text society to the target text society in a comprehensible manner. Translation no doubt has to rely heavily on information and abilities that are not specifically cultural and also linguistic. The traditional view that the problem is mainly a linguistic one is clearly not tenable. Translating as an activity and translation as the result of this activity are inseparable from the concept of culture which operates largely through translational activity. By the inclusion of new texts into another culture through translation that the particular culture undergoes innovation and it perceives the specificity of another culture. The translated work or the target text becomes the identity of source culture for receiving culture. This is what is termed as "the identity forming power" of translations (Venuti 1998:68). 
Translation leads to the journey of the source text from the one culture to another culture of target text. It is thus the intercultural textual transference leading to transmigration of texts. Translation is of course a necessary condition of all scholarly works. Translation leads to the movement of the source text beyond the frontiers of its language and culture. Hence the demands of this inter-cultural textual transference are heavy. The danger of this transference is the texts can get distorted as they travel across time, place and cultural domains which are also possible within a relatively homogenous cultural milieu. Rendering the Source Text faithfully into another language complete with its cultural underpinnings is definitely difficult. The translator hence follows certain via media like transcreation, adaptation, representation and transformation. The study of translation becomes particularly interesting when textual tranference takes place across culture leading also to linguistic and cultural encounter. The history of the representation of the texts like the Ramayan illustrates the ways in which the travels of a text through time, space and cultural forms test the limits of translation and impose upon that text new forms of expressions. Translation in the realm of Cultural Studies has become significant for the way in which the languages shape the texts. While translation implies linguistic activity wherein the printed texts are rendered in different cultures and languages. An understanding of source language and target language where linguistic codes are transferred across linguistic and cultural boundaries have been the domain of Translation studies. Translation could thus be considered as a form of creative endeavour, circumscribed within the limits of cultural codes, structures, standards and so on.

Each culture has its own sign system distinct from other cultures. On the basis of this sign system or language cultures communicate. Thus one possibility to understand a culture is to learn the languages of that culture and also the sign system operating within the culture. The problem with the translator while transforming the text into another language, however is that the languages of culture are apt to vary from region to region and from community to community within the same region. As a result 
the meanings may become ambiguous and many a same words will have different cultural connotations. However, in the present context it should be added that translation activity is an activity that explains the mechanisms of culture. Translation and translating are concepts concurrent with an active culture and allow the readers in the situation of that culture.

Translator is usually considered a shadowy figure, a negotiator or a compromise seeking agent between two languages and two cultures. But his responsibilities are immense primarily to both the source language text and its target text culture. The translators have to transplant the spirit and the essence of the source text in the target text by de-familiarising the source language to suit the culture to the target text. They have to familiarise source language culture to target language culture. As the translators work through the languages of source and target texts, certain aspects of culture automatically get transferred into the target culture. The translators face uncertainty when they come across the impossibility to identify equivalent words, in familiarising or de-familiarising the source language on the complexities and difficulties involved in translating culture specific items. They can reinvent new techniques, new devices as they are available and also conveniently acceptable in the target text culture. They should translate what the author intends to say and not what he has written.

Translation fails or untranslatability occurs when it becomes impossible to build functionally relevant features of the situation into the contextual meaning of the target language text. Broadly speaking, the case of untranslatability where this happens fall into two categories - those where the difficulty is linguistic and those where it is cultural. The linguistic as well as cultural transference becomes problematic as one takes a look at the scene of multilingual and multi-cultural variety of Indian society. Most of the theories of translation formulated so far do not seem to have taken into consideration the variety and multiplicity of such a cultural scenario. There needs to be the formulation of a meta-theory that would take into account India's multi-linguistic and multicultural diversity. 
'Phaniyamma' is a novel written in Kannada by M. K. Indira in 1976. It has been translated into English as 'Phaniyamma' by Tejaswini Niranjana a renowned translation critic. She won the Sahitya Akademi award for her translation of Phaniyamma in 1993. The original title has been retained into English by the translator. The English translation of the novel becomes a powerful transmitter of the Indian traditional Brahmin society of Karnataka of 1970s and its culture to the English speaking audience not only across the country but the whole world. The Kannada words have been transcreated into English which demand an explanation e.g. the word 'madi' which is taken to mean a cleansed woman. The word has its cultural connotation. Such words need to be decoded in the footnotes. The eponymous protagonist of the novel becomes a widow at the age of nine. At the age of fourteen when she starts menstruating she is shaven off and made a'madi' woman and is forced to join the group of old widows at home. The mere transcreation of words with loaded cultural connotation cannot be totally comprehensible to the people belonging to other culture because many of such social practices are totally alien to other cultures of the world. The English translation - "Nor can she perform any "madi" task. The fourth day after she menstruates, her hair must be shaved off and she must be made to take up 'madi' for the rest of her life" (Niranjana 1994:46). The context of the novel may no doubt provide the hint of the situation but it is highly impossible to transfer the real connotation of a particular word into an alien language. Words like 'madi', 'mangalasutra' and many other words that are retained in the translated text are deeply loaded with cultural inferences and are not explained at all either directly or indirectly. Despite, Tejaswini Niranjana in her translation creates an ambience of Indian domestic and social context and is successful in maintaining the individual specificity of the Brahmin culture by documenting the specificities of local Brahmin customs, culture and Kannada language. Therefore she has retained the culture-specific terms like 'madi,' 'atte', 'mangalasutra,' 'sandige' and many more Kannada words are retained. These cultural limits on translatability occur due to the absence of a relevant similar situation in the target language culture. It creates difficulty in carrying across the ethos. 
Chandragiriya Tiradalli is a Kannada novel written by Sara Abubaker. It has been translated into English as Breaking Ties by Vanamala Viswanath, who employs the technique of transformation while translating. She clarifies, "The title could have been translated into English as On the Banks of Chandragiri to reflect its Kannada source. But since it sounded too literary to reflect the political edge to the book and some what familiar ... After a prolonged discussion on the implications of the title we selected the more neutral and nuanced title Breaking Ties" (Niranjana xix, xxi). Besides, the original title does not contain the sense of compulsion and severity underlying the social practice of 'talaaq' among the Muslims. The cultural conditioning of women in general and Muslim women in particular is successfully brought about in her translation. Here too, the translator retains the culture specific terms of Muslims like talaaq mehar, abba and others for which there is a glossary at the end. Both Tejaswini Niranjana and Vanamala Viswanath have consciously set themselves to the task of transferring the cultural situation through a foreign language for an audience which may not be familiar with the social and cultural situation. They are thus during their translation activity caught between the need of the local colour and the need to be understood by an audience outside the source text cultural and lingual situation. In order to convey the flavours of local culture both of them have retained the culture specific original words. The literal translation of such words would be jarring and clumsy.

The endeavorus of these translaters remind of what Horst Frenz has observed that translation is "neither a creative art nor an imitative art but stands somewhere between the two" (Frenz 1961:72-96) because a literal translation will distort the sense of the original cultural terms and may sound clumsy to target text readers. Hence a translator should try "to produce the source language in the target language while producing at the same an acceptable paraphrase of the sense" (Bassanet 1980:84). Translation can only be an adequate interpretation of an alien sign unit and so exact equivalence is impossible. Limits are imposed on translatability at all the levels - word, sentence, etc. 
Derrida prefers the term "Transformation" to translation (Michael Thomas 2006) for certain words that resist translation and which can only be transformed. Biological features no doubt are universal but not aesthetic concepts. Items of food, dress etc. differ from culture to culture, hence the translator has to retain the original words as the translators Niranjana and Vanamala have done.

India is a multi-lingual and multi-cultural in nature. So, none of the translation theories constructed in the 1960s on a purely linguistic basis are not adequate to meet all these multiple cultural requirements. The translation theories of 1960 s passed through the 1970s with their shift of focus from linguistic to the textual and have now reached a culture-based orientation. Translation is now viewed as establishing links between different cultures. A meta-theory has to be evolved taking into account the problematic situations faced by new translators in the multiplicity of cultures especially in the Indian context.

The texts that get translated need not be translated in purely linguistic terms. Apart from addressing the linguistic, semantic or cultural specific problems the translators are desired and proposed to address the ways in which translation crosses linguistic boundaries while re-casting and reinscribing the new spaces that are of cultural significance. It involves the selection of equivalents, in the manner of retaining culture specific items, in the selection of the language and of course the confidence in presenting it to the other culture. Sometimes the translator may be compelled to compromise in order to make the source text palatable to the target language readers. In the process the translator may follow the technique of addition, edition, deletion, suppression, mutilations and so on. Many a times the translators place themselves in a position of authority to decide what the target language reader should read. And ironically, the local cultural specificities will be deleted. Instead, a translator should follow a policy of italicising the culture-specific and locale-specific terms and must try to retain as far as possible the voice of the original author. 
Recognising such parametres can always lead to a certain degree of excellence in transferring source culture to the target culture. Such an objective orientation makes the translators confident without which they can not hope to be excellent even they are fully aware of the fact that in translation everything of the source text can not be transferred and that whatever they translate into the target culture text would generate another text altogether in a new culture.

Culture has always remained problematic to the translators. It is paradoxical that because of such a culture specific factor, translation becomes a necessity. It may be said that ultimately it is impossible to translate the words directly. Culture, on the other hand can not be translated directly without grotesque distortions. Nobody either Giovanni Pontiero or Ramanujan or for that matter any translator can even present a formulaic framework and solution to the complex and problematic area of culture in translation. A particular device used to overcome the linguistic and cultural problem in a particular text can not necessarily hold good to another text. Moreover while translating a particular text the translator must bear in mind that time and locale of the text where it is situated also matter much in context of culture. The translators have therefore to be dynamic and competent in their ability to comprehend the rich cultural nuances of source as well as target culture. They should have an understanding and competence to create a cultural context with items specific to recipient culture. However, this depends entirely on the translator's ability in making the right kind of selection in order to achieve excellence.

Theodor Savory in his The Art of Translation has presented the enormity of the complexities involved in translation. He also was unable to provide a clear cut solution for the problem. Whatsoever, the inter-cultural textual transference through translation bridges the gap between diverse cultures and makes available to readers outside one's own language and culture. The translators must be aware of and alive to the culture of their source language text and target language text before they attempt to build any bridge 
between them. While transferring the cultural material of the original composition the translators must strive to attain readability of their translated text in the new language.

\section{REFERENCES}

Bassanet, Susan. 1980. Ed. Translation Studies. London: Methuen.

Frenz, Horst. 1961. "The Art of Translation". Comparative Literary Method and Perspective. Ed. N.P.Stalknecht and Horst Frenz. Carbondale: Southern Illinois University Press.

Gentzler, Edwin. 2004. Contemporary Translation Theories. Shanghai: Shanghai Foreign Language Education Press.

Hermans, Theo. 2004. Translating in systems: Descriptive and Systemic Approach Explained. Shanghai: Shanghai Foreign Language Education Press.

Michael Thomas. 2006. The Reception of Derrida: Translation and Transformation, New York, NY: Palgrave MacMillan.

Niranjana, Tejaswini.1994. Phaniyamma., New Delhi: Kali for women, 2nd Ed.

Savory, Theodore. 1957. The Art of Translation. London: Jonathan Cape.

Soanes, Catharine and Angus Stevenson. 2008. Eds. Concise Oxford English Dictionary. 11th Ed. Revised. New Delhi: Oxford University Press.

Venuti, Lawrence. 1998. The Scandals of Translation: Towards an Ethics of Difference. Routledge. 